\title{
A capillary electrophoretic method for isolation and characterization of grape xylem proteins
}

\author{
Ashok K. Jain* and Sheikh M. Basha \\ Plant Biotechnology Lab., Center for Viticulture and Small Fruit Research, Florida A\&M University, Tallahassee, FL \\ 32307, USA. \\ Accepted 10 February 2003
}

\begin{abstract}
European (Vitis vinifera) and American (Vitis labrusca) grape species succumb to a bacterial disease known as Pierce's Disease (PD). In contrast, muscadine grape genotypes (Vitis rotundifolia) are tolerant/resistant to PD. This is due to the unique biochemical composition of muscadine xylem. However, because of low protein concentration, conventional methods such as low-pressure chromatography and PAGE are unsuitable for grape xylem protein characterization. In addition, these procedures are tedious, time-consuming and require large amount of sample. This study reports a procedure for isolating and separating proteins from muscadine and bunch grape xylem tissue. The procedure consists of separation of xylem from cortex and phloem, removal of pigments and other gummy substances from xylem with ethanol: ethylacetate (2:1) and subsequent Capillary Electrophoretic (CE) analysis of xylem protein extracts to achieve desired resolution. Number of peaks, peak height and areas, retention time and baseline position were used to compare resolution and study the effect of sample and separation buffer. Xylem tissue proteins extracted with $0.05 \%$ sodium borate buffer ( $\mathrm{pH} 8.3$ ) and subjected to CE using $1.2 \%$ sodium borate $(\mathrm{pH} 8.3$ ) as a separation buffer were found to yield most satisfactory resolution of grape xylem proteins. The data obtained by CE were consistent and reproducible, and hence, is well suited to obtain excellent resolution of xylem tissue protein for identifying differences in protein composition among the grape genotypes.
\end{abstract}

Key words: Capillary electrophoresis, grape, Vitis, xylem, Pierce's disease, protein.

\section{INTRODUCTION}

Grape (Vitis sp.) ranks as one of the most important fruit crop in the world (FAO Production Year Book, 1993). Commercial grape cultivation is dominated by bunch grape (Vitis vinifera L., V. labrusca L., and other Vitis spp.) and hybrids. Unfortunately, the commercially desirable grape genotypes, both the European type (Vitis vinifera) and American type (Vitis labrusca), succumb to the bacterial Pierce's Disease (PD) (Hopkins, 1984) and usually die once infected.

Pierce's disease is caused by a gram-negative bacterium (Davis et al., 1978) Xylella fastidiosa (Hopkins, 1989 ) and commonly known as the xylem-limited bacteria (XLB) (Hopkins, 1983). The marginal leaf burn (MLB) or leaf scorch are characteristic symptoms of the disease caused by restricted flow of water and nutrients as a result of bacterial multiplication in the xylem (Fry and Milholland, 1990) and partial or complete occlusion of individual conducting elements by bacterial plugs (Mollenhaur and Hopkins, 1974). As a result of plugging

${ }^{*}$ Corresponding Author; E-mail: ashok.jain@famu.edu, tel: (850) 561-2219, fax: (850) 599-3119 and subsequent water stress vines develop disease symptoms (Goodwin et al., 1988) and finally the plant dies over a period of years.

The muscadine genotypes [Vitis rotundifolia Michx. or alternatively, Muscadinia rotundifolia (Michx.) Small] (Hopkins et al., 1974; Mortensen et al., 1977) native to the southeastern United States are tolerant to PD. Although muscadine genotypes are known to tolerate PD, the molecular and biochemical basis of the resistance to PD has not been investigated. Studies on the microenvironment of xylem tissue and xylem sap of tolerant muscadine and susceptible bunch genotypes should help in understanding the basis of tolerance to PD infection. Currently we are involved in identifying differences in the protein/polypeptide composition of xylem tissue between PD tolerant muscadine genotypes and susceptible bunch genotypes. However, conventional methods such as PAGE, HPLC, low pressure chromatography, etc., are not successful in resolving xylem proteins because of low concentration, and difficulty in obtaining large volumes of xylem sap from the vines throughout the growing season especially muscadine genotypes. Branches of thoroughly watered muscadine vine did not bleed when they were cut except 
few drops of sap dripped from two or three branches. Hence, there was a need to develop a sensitive technique to resolve xylem proteins for determining compositional differences between bunch and muscadine grape genotypes, and to monitor changes in xylem protein composition in response to Xylella infestation.

Hence, in this study an attempt was made to evaluate the suitability of capillary electrophoresis (CE) for analyzing the protein/polypeptides from xylem tissue of bunch and muscadine grape genotypes. The method would be applied to monitor changes in xylem protein composition in response to Xylella infestation. The relative profile of xylem protein during disease development between PD tolerant and susceptible grape genotypes would help in understanding the biochemical basis of PD tolerance.

\section{MATERIALS AND METHODS}

\section{Plant Material}

Four years old plants of muscadine (Vitis rotundifolia Michx, cv. Noble) and Florida bunch hybrid (Vitis sp., cv. Blanc du Bois), grown in the field plots at the Center for Viticulture and Small Fruit Research, Florida A\&M University, Tallahassee, FL were used in the study. Young shoots ( 40 to 45 days of spring growth) from these plants were collected and transported to the lab on ice. The xylem tissue with pith (between 5th and 10th internodes from the apical tip) was separated from the cortex and phloem by making a longitudinal cut and peeling off the cortex-phloem tissue. The xylem tissue was cut into small pieces (5 to $7 \mathrm{~mm}$ ) and ground using a mortar and pestle. The ground tissue was stored at $-20^{\circ} \mathrm{C}$ and used for method development.

\section{Protein Extraction}

Initially we had employed the CE procedure optimized earlier for peanut seed proteins (Basha, 1997) and also recommended for other crops by the manufacturer (Chen, 1991; Palmieri, 1989) for the extraction of protein from the grape xylem tissue. The ground xylem tissue was homogenized with $0.3 \%(\mathrm{w} / \mathrm{v})$ sodium borate buffer, $\mathrm{pH} 8.3$ (tissue to solvent ratio $1: 5 \mathrm{w} / \mathrm{v}$ ) using a Polytron homogenizer (Brinkman Instruments, Inc. Westbury, NY). The homogenate was centrifuged $\left(20000 \mathrm{~g}, 15 \mathrm{~min}, 4{ }^{\circ} \mathrm{C}\right)$, filtered through a $0.2 \mu \mathrm{m}$ filter and the filtrate used for Capillary Electrophoresis (CE). A portion of the filtrate was used to analyze the total protein concentration in the xylem extract (Lowry et al., 1951).

Usage of crude xylem extract in CE resulted (data not shown) in a protein profile with high background and unresolved peaks indicating that the crude extract contained significant amounts of UV absorbing compounds such as pigments, amino acids, etc., that interfered with protein separation. Subsequently, modifications were made to the sample preparation and protein extraction protocols for removing interfering compounds and to improve protein resolution during $\mathrm{CE}$. The crude tissue was pre-extracted with various organic solvents to solubilize the interfering compounds. In this connection ethanol, methanol, acetone, chloroform, ethylacetate, ether, acetonitrile, etc., were evaluated in various combinations to determine their efficiency in removing the non-protein UV absorbing compounds.

\section{Capillary Electrophoresis (CE)}

CE separation was performed on a Beckman P/ACE 2100 System (Beckman Coulter, Palo Alto, CA) controlled by a computer equipped with System Gold software ${ }^{\circledR}$ (Version 6.0). The protein separation was performed in uncoated fused silica capillary $(75 \mu \mathrm{m}$ i.d. $x 57 \mathrm{~cm}$ ). Electrophoresis was conducted at $25{ }^{\circ} \mathrm{C}$ and voltage of $10 \mathrm{kV}$. The detector was set at $214 \mathrm{~nm}$, and $12 \mathrm{~nL}$ of sample was injected $(20 \mathrm{~s})$. The capillary was rinsed sequentially between successive electrophoretic runs with $0.1 \mathrm{~N}$ sodium hydroxide (5 $\mathrm{min})$, deionized water $(3 \mathrm{~min})$ and separation buffer. The concentration of separation [sodium borate buffer $(0.3 \%, 0.6 \%$, $0.9 \%, 1.2 \%$ and $1.5 \%), \mathrm{pH} 8.3]$ and sample extraction buffers [sodium borate buffer $(0.025 \%, 0.05 \%, 0.1 \%, 0.15 \%), \mathrm{pH} 8.3$ ] was modified to accomplish the desired protein resolution. Several injections (at least three) of each extract were made with separation buffer to observe the resolution, efficiency and repeatability of protein peaks. Detection of peaks, peak sharpness (peak heights and areas), retention times and baseline positions of each run was used to determine the effect of sample and separation buffers with resolution, efficiency and repeatability of protein profile.

\section{RESULTS}

The total protein concentration in the xylem extract varied greatly between bunch (Blanc du Bois with $0.468 \%$ ) and muscadine (Noble with $0.854 \%$ ) grape fresh xylem tissue. Initially $0.3 \%$ sodium borate buffer $(\mathrm{pH} 8.3)$ was used for sample extraction and electrophoretic separation buffers to develop the CE procedure for extracting and separating grape xylem tissue protein. However, this procedure did not resolve grape xylem proteins satisfactorily, and resulted in poor peak resolution and a high background. Hence, it was necessary to optimize the sample and separation buffer concentrations to obtain satisfactory resolution of grape xylem proteins. This is essential in our studies aimed at determining the genetic differences in xylem protein composition and its affect on grape plant susceptibility to PD.

\section{Effect of sample preparation on xylem protein resolution}

Extraction of fresh xylem tissue directly with $0.3 \%$ sodium borate buffer, $\mathrm{pH} 8.3$ and its usage in CE resulted (data not shown) in a protein profile with high background and unresolved peaks indicating that the crude xylem extract contained significant amounts of UV absorbing compounds such as pigments, amino acids, etc., that interfered with protein separation. Hence, the crude tissue was pre-extracted with various organic solvents to solubilize the interfering compounds. In this connection ethanol, methanol, acetone, chloroform, ethylacetate, ether, acetonitrile, etc., were evaluated in various combinations to determine their efficiency in removing the non-protein UV absorbing compounds. These studies revealed that a mixture of ethanol:ethylacetate $(2: 1)$ as the best solvent combination for removing majority of the interfering compounds from grape xylem tissue. All 
experiments reported below employed the xylem tissue that was pre-extracted with ethanol:ethylacetate $(2: 1, v: v)$ twice, followed by once with acetone and air dried.

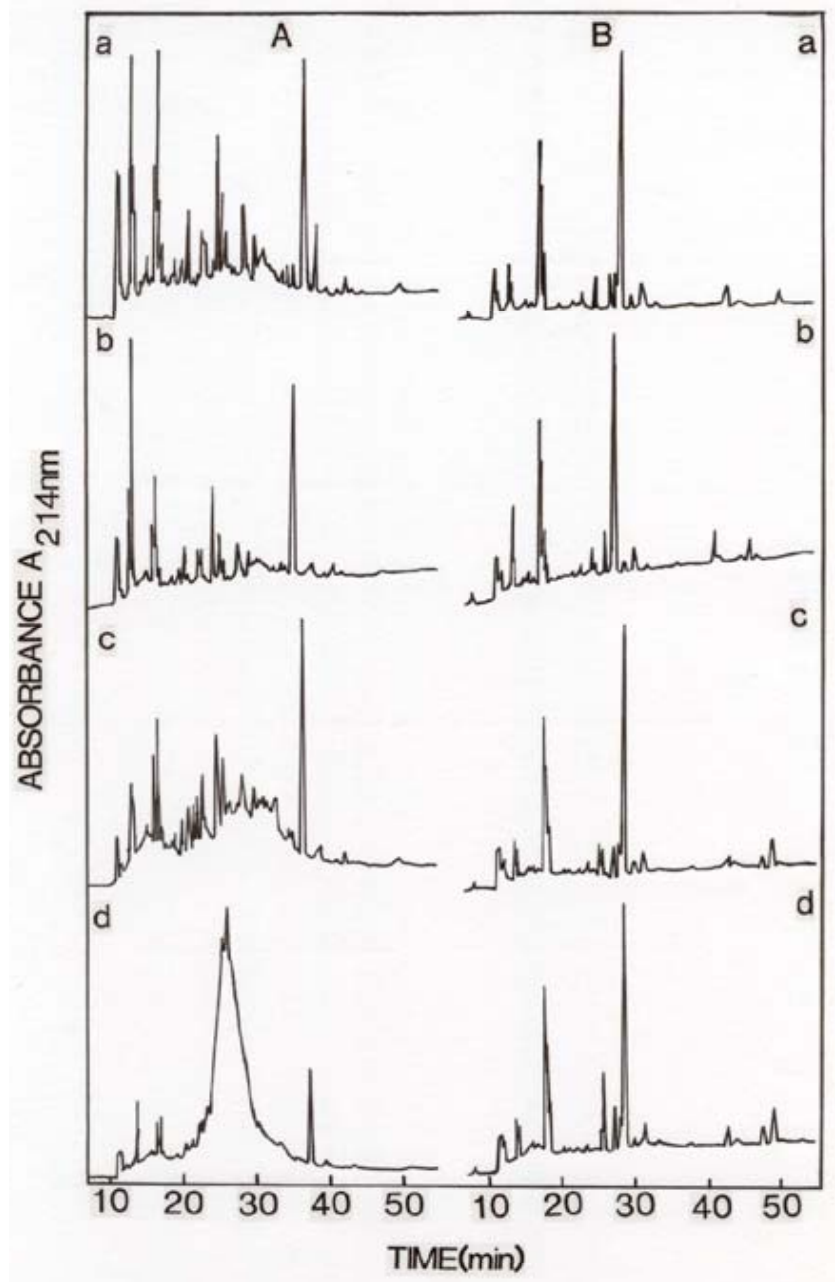

Figure 1. Effect of sample buffer concentration on grape xylem tissue protein resolution: $A=$ Noble (Muscadine), $B=$ Blanc du Bois (Bunch). Xylem tissue was extracted with different concentrations of sodium borate buffer $(\mathrm{pH} 8.3)$ a: $0.025 \%, \mathrm{~b}: 0.05 \%$, c: $0.1 \%$, d: $0.15 \%$ and subjected to CE using $1.2 \%$ sodium borate $(\mathrm{pH} 8.3)$ as the separation buffer.

\section{Effect of sample buffer concentration}

Xylem tissue protein was extracted with various concentrations $(0.025 \%, 0.05 \%, 0.10 \%$ and $0.15 \% ; \mathrm{w} / \mathrm{v})$ of sodium borate buffer, $\mathrm{pH} 8.3$ and analyzed by CE using $1.2 \%(\mathrm{w} / \mathrm{v})$ sodium borate, $\mathrm{pH} 8.3$ as the separation buffer. The results indicated (Figure 1) that the sample extraction buffer concentration had a significant effect on xylem protein resolution in both the muscadine $(A=$ Noble) and bunch ( $B=$ Blanc du Bois) grape genotypes. However, the effect was more evident in Noble xylem extract compared to Blanc Du Bois. As seen in the figure, high buffer concentration $(>0.15 \%)$ resolved xylem proteins poorly while low buffer concentrations $(<0.1 \%)$ gave relatively a better protein resolution. The number of peaks and peak area was affected greatly by increasing buffer concentration. The xylem extract of Noble resolved a total of 24 peaks when tissue was extracted in $0.025 \%$ buffer compared to only 9 peaks when tissue was extracted in $0.15 \%$ buffer. In Blanc Du Bois 17 peaks were resolved in $0.025 \%$ sample buffer compared to 11 peaks when tissue was extracted in $0.15 \%$ sodium borate buffer. Among the buffer concentrations, $0.025 \%$ and $0.05 \%$ sodium borate buffer $(\mathrm{pH} 8.3)$ concentrations yielded superior protein resolution. Of these two concentrations, $0.05 \%$ gave an improved resolution of proteins eluting between 20 and 30 min compared to the $0.025 \%$ buffer.

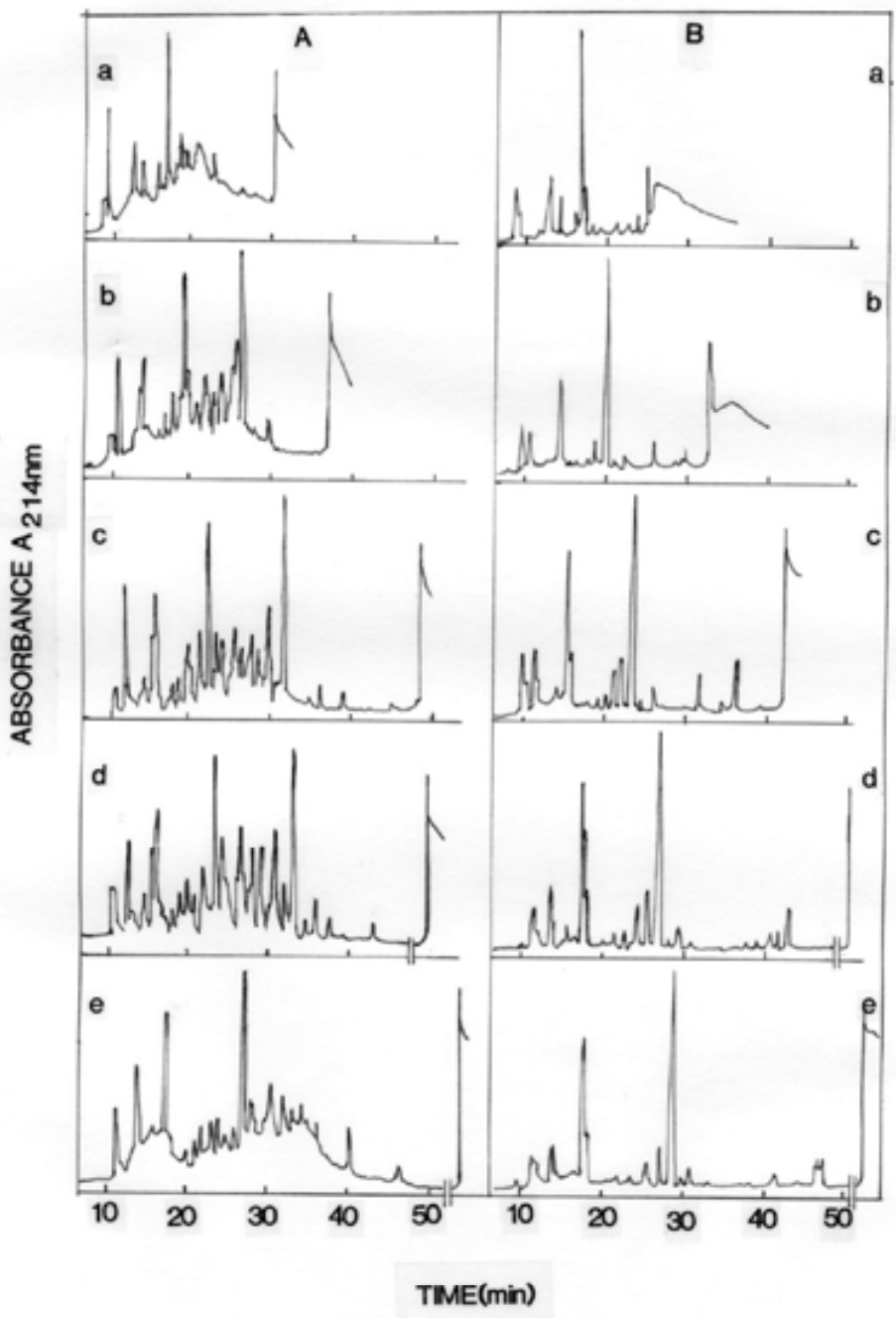

Figure 2. Effect of separation buffer concentration on grape xylem tissue protein resolution: $A=$ Noble (Muscadine), $B=$ Blanc du Bois (Bunch). Xylem tissue was extracted with $0.05 \%$ sodium borate buffer, $\mathrm{pH} 8.3$ and subjected to $\mathrm{CE}$ using various concentrations of sodium borate buffer, $\mathrm{pH} 8.3$ (separation buffer): a: $0.3 \%, \mathrm{~b}: 0.6 \%$, c: $0.9 \%$, d: $1.2 \%$ and e: $1.5 \%$. 


\section{Effect of separation buffer concentration}

Xylem tissue protein was extracted with $0.05 \%(\mathrm{w} / \mathrm{v})$ sodium borate buffer, $\mathrm{pH} 8.3$ and subjected to CE employing separation buffer concentrations between $0.3 \%$ and $1.5 \%$ (sodium borate, $\mathrm{pH} 8.3$ ). Resulting CE protein profiles of xylem tissue from muscadine (Noble) and bunch (Blanc du Bois) grape genotypes are shown in Figure 2. CE resolved grape xylem proteins into more than 20 components. Protein resolution improved with increasing concentration of the separation buffer up to $1.2 \%$ and then declined. The effect was more evident in Noble xylem extract compared to Blanc Du Bois. In case of Noble the elevated base line in low and high separation buffer concentration also affected the peak resolution. High separation buffer concentrations also increased duration of the run. For example, with $0.3 \%$ separation buffer, most of the proteins eluted within 30 min of injection while it took more than 60 min with $1.5 \%$ separation buffer. Of the separation buffer concentrations, $1.2 \%$ sodium borate buffer $(\mathrm{pH} 8.3)$ gave the best resolution compared to the other buffer concentrations. Multiple xylem extracts from both the muscadine and bunch grape genotypes behaved similarly with different sample and separation buffer concentrations suggesting that this protocol would be applicable to both the muscadine and bunch genotypes.

\section{DISCUSSION}

The present study demonstrates major differences in the protein profile between Florida bunch (Blanc Du Bois) and muscadine (Noble) grape xylem tissue. There are limited studies with application of capillary electrophoresis in genetic analysis to evaluate polymorphism of some specific proteins (Reico et al., 1997; Gerber et al., 2000). However, it offers the opportunity to quantify each of these components. By this way it provide an access to an aspect of regulation process, which could better explain the quantitative trait variation observed between individuals. Polymorphism in gene regulation is thought to be an important basis for phenotypic changes (Damerval et al., 1994). Moreover, the study of proteins, which collaborate to the building of the phenotype, may help to understand it better and may be valuable tools to dissect quantitative traits, compared to DNA markers with no phenotypic meaning. Relationship between agronomical traits and protein quantity variation has been demonstrated in maize (Leonardi et al., 1991) and pine (Gerber et al., 1997). The ease of separation of grape xylem proteins and the unique capillary electrophoretic patterns that exist between grape genotypes indicate that xylem proteins could be used to compare the xylem protein profile between susceptible and tolerant genotypes. This CE method will be applied to monitor the proteins peaks, their comparison between PD tolerant and susceptible genotypes within bunch and/or within muscadine genotypes that would allow a better description of the biochemical and genetics of xylem tissue in grapes.

The overall results indicated that CE effectively resolved grape xylem proteins from both muscadine and bunch grape genotypes when protein was extracted from the pre-processed tissue and subjected to CE employing appropriate separation buffer. Because of its sensitivity and low sample requirement, the CE may serve as a primary choice for determining compositional differences in xylem proteins between PD susceptible and tolerant grape genotypes.

\section{ACKNOWLEDGEMENT}

This research was supported by Florida Department of Agriculture, Viticulture Advisory Council Grants \# FDACS 006362 and 006361.

\section{REFERENCES}

Basha SM (1997). Separation of peanut proteins by capillary electrophoresis. J. Agric. Food Chem. 45:400-402.

Chen FA (1991). Protein separation by P/ACE System 2000 capillary electrophoresis on fused-silica columns. Beckman Technical Information, DS-818.

Damerval C, Maurice A, Josse JM, de Vienne D (1994). Quantitative trait loci underlying gene product variation: a novel perspective for analyzing regulation of genome expression. Genetics 137:289-301.

Davis MJ, Purcell AH, Thomson SV (1978). Pierce's disease of grapevines: Isolation of the causal bacterium. Science 199:75-77.

FAO Production Year Book (1993). Food and Agriculture Organization of the United Nations, Rome. Vol. 46.

Fry SM, Milholland RD (1990). Response of resistant, tolerant, and susceptible grapevine tissues to invasion by the Pierce's disease bacterium. Xylella fastidiosa. Phytopathology 80:66-69.

Gerber S, Lascoux M, Kremer A (1997). Relation between protein markers and quantitative traits in maritime pine (Pinus pinaster Ait.). Silvae Genet. 46:286-291.

Gerber S, Fabre F, Planchon C (2000). Genetics of seed quality in soybean analysed by capillary gel electrophoresis. Plant Sci. 152:181-189.

Goodwin PH, DeVay JE Meredith CP (1988). Roles of water stress and phytotoxins in the development of Pierce's disease of the grapevine. Physiol. Mol. Plant Pathol. 32:1-15.

Hopkins DL (1983). Gram-negative xylem-limited bacteria in plant disease. Phytopathology 73:347-350.

Hopkins DL (1984). Variability of virulence in grapevine among isolates of the Pierce's Disease bacterium. Phytopathlogy 74:1395-1398.

Hopkins DL (1989). Xylella fastidiosa: Xylem-limited bacterial pathogen of plants. Annu. Rev. Phytopathol. 27:271-290.

Hopkins DL, Mollenhauer HH, Mortensen JA (1974). Tolerance to Pierce's disease and the associated rickettsia-like bacterium in muscadine grape. J. Amer. Soc. Hortic. Sci. 99:436-439.

Leonardi A, Damerval C, Hebert Y, Gallais A, de Vienne D (1991) Association of protein amount polymorphism (PAP) among maize lines with performances of their hybrids. Theor. Appl. Genet. 82:552560.

Lowry OH, Rosebrough NJ, Farr AL, Randall RJ (1951). Protein measurement with Folin-Phenol reagent. J. Biol. Chem. 193:265-387.

Mollenhauer HH, Hopkins DL (1974). Ultrastructural study of Pierce's Disease bacterium in grape xylem tissue. J. Bacteriol. 119:612-618. 
Mortensen JA, Stover LH, Balerdi CF (1977). Systematic resistance to Pierce's disease in Vitis. J. Amer. Soc. Hort. Sci. 102:695-697.

Palmieri R (1989). Analysis of recombinant human growth hormone by capillary electrophoresis with P/ACE System 2000. Beckman Application Data, DS-749.

Recio I, Ramos M, Amigo L (1997). Study of the polymorphism of ovine $\alpha_{S_{1}-}$ and $\alpha_{S_{2}}$-caseins by capillary electrophoresis. J. Dairy Res. 64:525-534. 